\title{
Matrices virtuelles HLA pour la prédiction d'épitopes vaccinaux
}

\section{Vincent Lotteau}

V. Lotteau: Insserm U.503, Immunobiologie moléculaire, École Normale Supérieure de Lyon, 46, allée d'Italie, 69364 Lyon Cedex 07 , France.

synthétisées par la cellule (peptides viraux par exemple). Les trois autres codent pour les protéines du $\mathrm{CMH}$ de classe II qui présentent surtout les antigènes $d$ 'origine extracellulaire (par exemple: certaines bactéries). Le $\mathrm{CMH}$ de classe II présente les peptides antigéniques aux lymphocytes T CD4 qui règlent les réponses cellulaires et humorales.

Les antigènes ne sont pas présentés par le $\mathrm{CMH}$ sous forme native, mais après dégradation en peptides de 8 à 18 acides aminés. Pour déclencher une réponse immunitaire, une protéine doit donc être dégradée en peptides, et ces peptides doivent pouvoir se fixer sur le $\mathrm{CMH}$. Puisque la formation des complexes peptide- $\mathrm{CMH}$ est une condition nécessaire, bien que non suffisante, à la production d'un bon épitope vaccinal, la caractérisation des séquences peptidiques qui peuvent se fixer à une grande variété de protéines du $\mathrm{CMH}$ est une étape indispensable à la fabrication de vaccins synthétiques.

\section{Les peptides antigéniques se lient à des poches du sillon HLA}

\section{La présentation} des antigènes peptidiques

Chaque individu a sa propre capacité de défense contre un antigène, qui est déterminée génétiquement par les molécules du complexe majeur d'histocompatibilité $(\mathrm{CMH})$. Le CMH comporte 6 loci très polymorphes. Trois loci codent pour les protéines du $\mathrm{CMH}$ de classe I qui présentent généralement les peptides des protéines
La cristallographie a montré que le dimère HLA-DR (un des trois complexes du $\mathrm{CMH}$ de classe II chez I'homme) possède un sillon dans lequel peuvent s'insérer des peptides. Le sillon contient des poches qui interagissent avec les chaînes latérales des peptides [1-3]. Ces poches sont constituées d'acides aminés polymorphes et se distinguent par leur taille et leurs caractéristiques chimiques. Certaines chaînes latérales des peptides, quand elles entrent en contact avec les poches, augmentent l'affinité des peptides pour le sillon, d'autres la diminuent [4]. La spécificité d'une poche peut donc être définie à la fois par une analyse topographique (définition des acides aminés qui la constitue) et une analyse fonctionnelle. Celle-ci consiste à substituer successivement l'acide aminé du peptide ligand correspondant à cette poche par tous les autres acides aminés, puis à quantifier les conséquences de chaque substitution sur la liaison du peptide dans le sillon. On obtient alors un profil pour chaque poche, et la somme de tous les profils, pour un allèle HLA-DR donné, définit une matrice quantitative [5].

\section{Indépendance allélique des profils de liaison et prédiction d'épitopes}

Dans cet article, les auteurs montrent que le profil d'une poche est presque indépendant de la variabilité génétique du reste du sillon [1]. Donc, le profil d'une poche est identique quel que soit l'allèle HLA-DR tant que les acides aminés qui la constituent restent identiques. En conséquence, un petit nombre de profils peut être attribué à un grand nombre d'allèles HLA-DR par simple comparaison de séquences. Ces matrices virtuelles couvrent la majorité des spécificités HLA-DR.

A partir de la séquence d'une protéine, l'algorithme de matrice identifie 
$d^{\prime}$ abord tous les cadres peptidiques potentiels d'une certaine longueur. Puis, des valeurs sont attribuées à chaque acide aminé de ces cadres, en fonction de sa position et de sa spécificité d'interaction avec la poche. Une valeur globale est ensuite attribuée à chaque peptide et donne un "score» peptidique. Ces «scores" peptidiques sont bien corrélés avec l'affinité des différents peptides pour le sillon, ce qui montre que l'algorithme peut être utilisé pour analyser le potentiel immunogène d'une protéine de séquence connue. En le couplant à la technologie des puces à ADN, les auteurs ont sélectionné, à partir de 20000 gènes, des épitopes spécifiques du cancer du côlon, candidats potentiels à un vaccin synthétique. II convient malgré tout d'être prudent car la spécificité d'expression des antigènes tumoraux n'est pas absolue, et la réponse immunitaire antitumorale restreinte par le $\mathrm{CMH}$ de classe II est sans doute moins importante que celle restreinte par le $\mathrm{CMH}$ de classe I. Quoi qu'il en soit, cette technologie est rapide et permet de réduire considérablement le nombre d'épitopes candidats qui seront testés par les techniques plus traditionnelles beaucoup plus lourdes

\section{RÉFÉRENCES}

1. Sturniolo T, Bono E, Ding, et al. Generation of tissue-specific and promiscuous HLA ligand databases using DNA microarrays and virtual
HLA class II matrices. Nat Biotechnol 1999; $17: 555-61$.

2. Stern LJ, Brown JH, Jardetzky TS, et al. Crystal structure of the human class II MHC protein HLA-DR1 complexed with an influenza virus peptide. Nature 1994; 368: 215-21.

3. Brown JH, Jardetzky TS, Gorga JC, et al. The three dimensional structure of the human class II histocompatibility antigen HLA-DR1. Nature 1993 ; 364: 33-9.

4. Dessen A, Lawrence MC, Cupo S, et al. Xray crystal structure of HLA-DR4 (DRA 0101, DRB1 0401) complexed with a peptide from human collagene II. Immunity 1997; 7 : 47381.

5. Sinigaglia F, Hammer J. Defining rules for the peptide-MHC class II interaction. Curr Opin Immunol 1994; 6: 52-6.

\section{FONDATION AGF ATHENA}

$$
\text { INSTITUT DE FRANCE }
$$

